\title{
Hieu Nguyen and Sukanlaya Sawang* Juggling or Struggling? Work and Family Interface and Its Buffers among Small Business Owners
}

DOI 10.1515/erj-2014-0041

Published online September 30, 2015

\begin{abstract}
This study responds to calls for theory and research on work-family aspects in entrepreneurship research. This study examines the role of work-family conflict, work-family enhancement and social support on small business owners' (SBOs) well-being. Drawing from The Household Income and Labour Dynamics in Australia (HILDA) panel data, the sample is restricted to SBOs, married with children under the age of 14 during 2010-2011 (two waves), totaling 167 SBOs. Results revealed that work-family conflict has a negative direct effect on mental health, job, family and life satisfactions. Similarly, work-family enhancement was found to have a direct positive effect on job, family and life satisfaction but not mental health. A significant interaction term also suggested that work-family enhancement moderated the relationship between work-family conflict and SBOs' job satisfaction. Finally social support was found to have positive main effect on both subjective and psychological well-being. The interventions to well-being of SBOs should aim to balance the work and family lives of SBOs as well as making sure they have adequate social support networks. For public policy makers, support programs should extend from traditional means to balancing work-family matters for this particular occupation. Aside from broadening existing knowledge on the effects of work-family conflict, enhancement and social support, this is one of the first studies to examine well-being as a measure of success for SBOs. Additionally, the use of cross-wave data in the present study helps us to reduce this problem and provide a much stronger causal relationship between the focal variables of interest.
\end{abstract}

Keywords: small business owners, self-employed, entrepreneurship, work-family interface, social support, subjective and psychological well-being

In recent years, the restructuring and downsizing of large businesses provided opportunities for career advancements in small businesses. The increase of

\footnotetext{
*Corresponding author: Sukanlaya Sawang, QUT Business School, Queensland University of Technology, GPO Box 2434, Brisbane, QLD 4001, Australia, E-mail: s.sawang@qut.edu.au Hieu Nguyen, School of Psychology and Counselling, Queensland University of Technology, Brisbane, QLD, Australia
} 
small business owners (SBOs) has been documented to play a fundamental role in Australia's economy and production (Department of Innovation Industry, Science and Research [DIISR] 2011). Of the four million businesses in the private nonfinancial sector (e.g., agriculture, construction and manufacturing), 50\% are owned and operated by SBOs (DIISR 2012). Moreover between 2010 and 2011, small businesses added 34\% to Australia's industry value (gross domestic product; DIISR 2012). While there has been a strong growth in the number of SBOs, research on entrepreneurs and their experience of work-family conflict and its impact on psychological well-being is still relatively limited (Kirkwood and Tootell 2008; Shelton 2006). Moreover, existing entrepreneurship research has been criticized for neglecting the impact of SBOs' personal lives on their business-related endeavors (Jennings and McDougald 2007). More recent research has adopted the concept of family embeddedness, suggesting that business and family lives of SBOs are interdependent matters (De Bruin and Dupuis 2004; Dyer 2003; Jennings and McDougald 2007). Consequently, the present study aims to further the understanding of SBOs' personal lives by integrating work-family and well-being perspectives, which are a rich and relevant body of literature in psychology but remaining relatively untapped by entrepreneurship scholars. For the purpose of the present study, in line with the ABS (2001) definition of small businesses, SBOs will be defined as individuals who own and manage their own business.

Our study makes three primary contributions to the psychology and entrepreneurship literatures. First, our study responds to calls for theory and research on work-family aspects in entrepreneurship research. The importance of workfamily interaction and well-being has constantly been highlighted by previous studies and postulated to accentuate SBOs' performance and well-being (Chay 1993; Hahn, Frese, Binnewies, and Schmitt 2012; Kim and Ling 2001). Much relevant past research often examined work-family conflict as (a) a dependent variable (DV, e.g., factors which produce work-family conflict), (b) a predictor variable (e.g., the effect of work-family conflict on career, family and life satisfactions), and (c) measure of economic well-being (Hahn et al. 2012; Parasuraman et al. 1996). However, newer research suggests that work-family enhancement, a positive construct of work-family domain, provides a richer and more complete picture of the work-family interface. This positive view has gained prominence in the work-family research. Working overtime, for example, can definitely cause work-family conflict for workers (McNall, Nicklin, and Masuda 2009). However, it can also lead to many positive outcomes such as coping skills and multitasking skills, which can serve to improve performance in parenting roles and thereby benefiting family relationships (McNall, Nicklin, and Masuda 2009). In relation to SBOs, research notes that the nature of SBOs' work 
is predominately flexible (e.g., no specific work hours; Gorgievski, Ascalon and Stephan 2011; Jennings and McDougald 2007). On the one hand, flexible hours allow SBOs to work overtime, which may reduce the time they allocate for family responsibilities, and subsequently lead to work-family conflict (Kirkwood and Tootell 2008). On the other hand, flexible hours may allow SBOs to have more control over their work and attend to family matters more frequently than do organizationally employed individuals (McNall, Nicklin, and Masuda 2009). Ultimately, the nature of SBOs' work can have both benefits and deleterious effects on their work and family lives. Thus, it is evident that the work-family interface needs to be examined from both the negative (conflict) and positive (enhancement) aspects in order to develop an accurate understanding of this phenomenon. Therefore, in our study, we aim to assess both work-family conflict and enhancement, when investigating the impact work-family interface has on SBOs' well-being.

Second, our study extends the existing knowledge of relationship among conflict and enhancement of work-family interface. Past researchers who examined the effect of these two constructs (conflict and enhancement) only assumed the independent effect of them on DVs (Gareis et al. 2009). That is, these studies have generally examined the main effects of work-family conflict and enhancement while disregarding the potential moderating effects of these constructs. In the present study, we postulate that although work-family conflict can impact on individuals' well-being, the perception of work-family enhancement or social support is likely to promote spillover into the conflict and well-being relationship. The concept of enhancement is defined as participation in one life role being made easier through participation in another (Butler et al. 2005; Grzywacz and Bass 2003). Similarly, social support is understood as the perception and actuality that one has assistance from other people (Michel et al. 2010). These concepts can be considered as supportive resources for individuals in times of conflict. Aligning with Clark's (2000) Border Theory, (1) permeable and flexible borders and (2) the support of border-keepers can act as resources and can buffer the negative impact of job stress and individuals' well-being. Resources refer not to what people do, but to what is available to them in their work and life domains. These resources can be physical, psychological or social aspects. Consequently, the present study will utilize work-family enhancement and social support as two key resources to examine the buffering effect on workfamily conflict and well-being.

Third, unlike other small business and entrepreneurship research that heavily focuses on economic measures as the outcome, the present study aims to further our understanding of SBOs' well-being. It was originally believed that SBOs' career success was exclusively measured through their 
business's financial criteria (e.g., profit, number of sales, number of employees and turnover costs; Chaganti and Schneer 1994; Dess 1984; Loscocco and Roschelle 1991). However, in light of newer research, studies have argued that financial criteria are not the only form of success that SBOs strive for. According to Chay (1993), some SBOs place a heavy emphasis on being physically and mentally healthy rather than being financially successful. To them, having a healthy work and family life is considered to be a form of success. This finding was also supported by international studies which have shown that SBOs' mental health was a stronger predictor of success than financial criteria (Lee and Peterson 1998; Srivastava, Locke, and Bartol 2001). In our study, we suggest that well-being should be captured through different measures of subjective and psychological well-being. Subjective well-being is associated with happiness and is often defined as the positive and negative affective balance (Linley et al. 2009). On the other hand, psychological well-being is defined as individuals' psychological functioning (i.e., individuals' mental health; Chay 1993; Ryff 1989; Keyes, Shmotkin, and Ryff 2002).

Finally, work-family conflict and enrichment are assumed to be bidirectional, from work to family and vice versa. The present study, however, focuses on examining conflict and enhancement stemming from work because it is more likely that SBOs can directly influence how the business is operated than what happens in the nonwork domain. SBOs would have much influential authority to provide a strategic direction of the business in order to reduce work-family conflict and increase positive spillover between work and family. That is, it would be much more straightforward for SBOs to change their work operation than try to change family agenda. Further, research indicates that the family domain is more permeable than the work domain, making work more likely to impact family than the reverse (Butler et al. 2005; Kirkwood and Tootell 2008; Shelton 2006). Thus, investigating how work experience might positively influence on family domain carries the opportunity to provide practical recommendations for small business strategic management to enhance SBOs' well-being, which in turn could affect their business performance.

The remainder of this paper is organized as follows. Next, we review the relationship between work-family conflict and well-being. We then identify the potential buffering variables between work-family conflict and well-being, i.e., work-family enhancement and social support. The key hypotheses are then developed and follow with methodology, results and analysis explanation. Finally, the discussion and implications are presented. The conceptual model that guided our research is presented in Figure 1. 


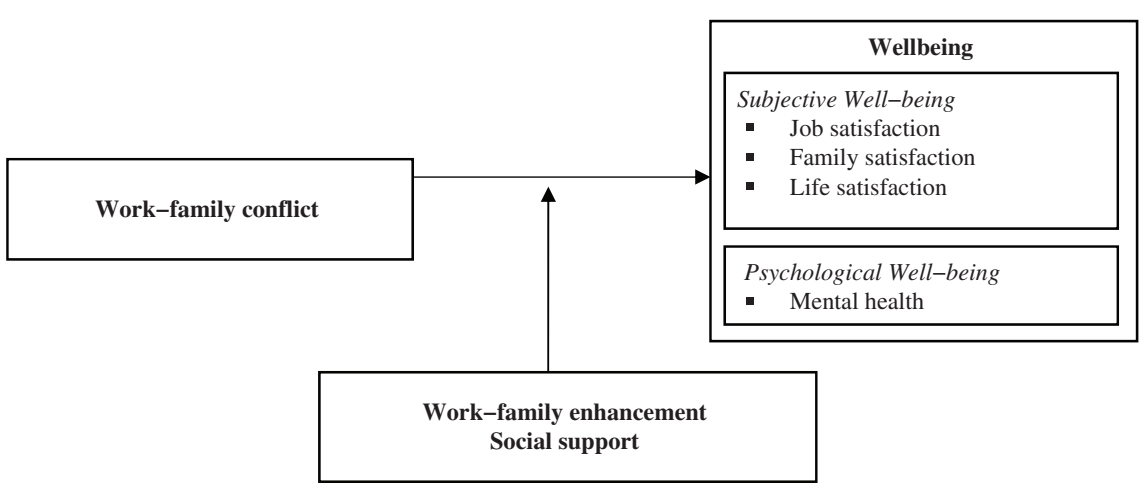

Figure 1: Predicted research model for the present study.

\section{Work-to-Family Conflict and Well-Being}

Demands for presence and commitment do not derive only from work but also from the home. Although these demands are not necessarily negative, they can turn into work-family stress when there is an imbalance between work and family demands. This is because individuals have a limited amount of attention and time. According to past studies, the participation in multiple roles (e.g., work and family), if not managed properly, could swiftly drain an individual's physical and psychological resources (Boyar and Mosley 2007; Grzywacz and Bass 2003; Grönlund 2007). That is, the participation in, for example, work roles is likely to reduce resources available for the participation in family roles, which in turn results in role conflict (Boyar and Mosley 2007). This phenomenon is akin to work/family Border Theory, which explains how individuals manage work and family domains, and the borders between them to obtain work-family balance (Clark 2000).

According to Clark (2000), individuals are "border-crossers who make daily transitions between [work and family] settings, often tailoring their focus, their goals, and their interpersonal style to fit the unique demands of each" (pp. 750751). In this sense, borders are lines of demarcation between work and family domains that influence individuals' degree of segmentation or integration between these domains (Clark 2000). Integration is achieved when individuals have fully integrated work and family domains, or, in other words, attaining work-family balance (Clark 2000). In contrast, segmentation is believed to be associated with inter-role conflict whereby individuals struggle to balance conflicting demands from work and family domains (i.e., work-family conflict or dissatisfaction and bad functioning in these areas; Clark 2000). 
Accordingly, work-family conflict is a common type of inter-role conflict "in which the role pressures from the work and family domains are mutually incompatible in some respect" (Greenhaus and Beutell 1985, 77). It resolves around the idea that increased demands in one role (such as work) result in preoccupation in that role and leads to difficulty with engaging in another role (such as family; Boyar and Mosley 2007). Work-family conflict can be based on the competitive demands for time, the depletion of personal resources as a result of physical and psychological strain and in-role behavior (Edwards and Rothbard 2000; Greenhaus and Beutell 1985). This view is also consistent with the role scarcity perspective explaining that individuals have limited time and energy to spend (Ruderman et al. 2002).

A substantial body of research has associated work-family conflict with many detrimental consequences, particularly negative impacts on individuals' well-being (Frone, Yardley, and Markel 1997). Well-being refers to a stable state of being well and feeling satisfied (Abele and Spurk 2009). Broadly speaking, studies of well-being have categorized it into two core dimensions of subjective well-being or psychological well-being (Bradburn 1969; Ryff and Keyes 1995). Subjective well-being is defined as individuals' cognitive (peoples' belief about their life satisfaction) and affective (positive and negative feelings) evaluations of their lives (Linley et al. 2009), while psychological well-being is understood as the "engagement with existential challenges of life" (Keyes, Shmotkin, and Ryff 2002, 1007). Subjective well-being is often measured by a person's affect, job satisfaction, marriage satisfaction, family satisfaction and life satisfaction (Diener et al. 1999; Pinquart and Sörensen 2000; Schimmack et al. 2002). In contrast, the conceptualization of psychological well-being was developed and termed mental health (Steel, Schmidt, and Shultz 2008). Mental health measures encompass a variety of theoretical concepts such as an individual's vitality and emotionality (Stephan and Roesler 2010) and are widely acknowledged due to their high psychometric values (Cole, Daly, and Mak 2009; Pirkis et al. 2005). In the present study, we employ the term well-being to capture both the subjective and psychological aspects.

Work and family conflict generally leads to decrements in the psychological well-being of individuals (Frone, Russell, and Cooper 1992; Frone, Yardley, and Markel 1997). Generally, studies of the physical health aspect of psychological well-being suggest that work-family conflict results in negative outcomes such as backache, dizziness, fatigue, headache and insomnia (Kinnunen and Mauno 1998; Netemeyer, Boles, and McMurrian 1996). More specifically, in the National Study of the Changing Workplace, Bond, Galinsky, and Swansberg (1998) highlighted that approximately 30\% of married men and women $(N=2,877)$ who are working reported having a significant amount of work and family conflict. 
These employees reported feeling more pressured to meet work responsibility in order to attain financial rewards that will assist with their family obligations.

Work-family conflict has also been shown to have a negative relationship with domain-specific measures of subjective well-being such as job satisfaction, family satisfaction (Pinquart and Sörensen 2000) and life satisfaction (Ernst and Ozeki 1998). A study by Ford, Heinen, and Langkamer (2007) proposed that dissatisfaction with life is attributed to work-family conflict. This is because work pressures reduce the time workers allocate for their family, which, in turn, leads to lower levels of life happiness (Aryee, Srinivas, and Tan 2005).

Although existing research has identified the negative impacts of workfamily conflict (e.g., Aryee, Srinivas, and Tan 2005; Frone, Russell, and Cooper 1992; Frone, Yardley, and Markel 1997), few have examined the influence of it on the well-being of SBOs. Due to the nature of SBOs' work (e.g., working overtime and therefore unable to attend to family responsibilities), they are more predisposed to accentuated experiences of work-family conflict (Kirkwood and Tootell 2008). Accordingly, in response to the proposed limitation, the present study will assess the relationship between work-family conflict and SBOs' well-being. Aligning with previous research, we hypothesize that:

Hypothesis 1 Work-family conflict will negatively affect SBOs' levels of subjective well-being [i.e., job satisfaction (H1a), family satisfaction (H1b), life satisfaction (H1c)] and psychological well-being [mental health (H1d)].

\section{Buffering Effects between Work-Family Conflict and Well-Being}

One model that may clarify the job characteristics associated with spillover between work and family is Border Theory (Clark 2000). As previously mentioned, borders can influence the degree of segmentation or integration between individuals' work and family domains. Clark (2000) additionally notes that the strength of a border is determined by its permeability, flexibility and blending. Permeability refers to the extent to which elements of work or family domain may enter the other. Permeations can be physical (e.g., physical walls around a family office) or psychological (e.g., positive/negative emotions spillover from work to family lives; Clark 2000). Flexibility, another pivotal border characteristic, is defined as "the extent to which a border may contract or expand, depending on the demands of one domain or the other" (Clark 2000, 757). When a border has high permeability and flexibility, this results in blending. 
Blending can be physical and psychological and occurs when work and family merge together, and can no longer be exclusively called either domain. An example of physical blending is when an entrepreneur is answering workrelated calls at home while simultaneously feeding her children. An example of psychological blending is when work-related skills are used to enrich home life. Finally, Clark's (2000) Border Theory also suggests that the supportiveness of border-keepers (e.g., family members or peers) can also enhance work-life balance (e.g., peers providing individuals with social support).

Aligning with Border Theory, we propose that (1) weak borders, characterized by high permeability and flexibility that allow blending, and (2) the support of border-keepers can act as resources to buffer the negative impact of job stress and individuals' well-being (Clark 2000). Resources refer not to what people do, but to what is available to them in developing their coping repertoire (Greenhaus and Powell 2006; Häusser et al. 2010). These resources are derived from an individual's work roles and can be psychological (personal skill/characteristics) or social (interpersonal network) aspects and can act as moderators to (1) influence the strength of the border between individuals' work and family domains, and (2) influence the strength and direction of the relationship between work-family conflict and well-being outcomes (Greenhaus and Powell 2006). Consequently, in the present study, we incorporate two key resources (work-family enhancement and social support) in order to gain a deeper understanding of their moderating effects on SBOs' work-family conflict and well-being.

\section{Work-Family Enhancement}

More recently, due to the positive psychology movement, researchers gained more interest in studying the enhancement perspective - a more positive aspect of work and family domain (Jennings and McDougald 2007; Wadsworth and Owens 2007). Work-family enhancement is defined as "the extent to which experiences in one role improve the quality of life in another role" (Greenhaus and Powell 2006, 73) and is conceptually independent from work-family conflict (Shockley and Singla 2011). The concept of work-family enhancement is depicted by interchangeable terms such as work-family enrichment (Wayne, Randel, and Stevens 2006), enhancement (Greenhaus, Ziegert, and Allen 2012), facilitation (Wayne, Musisca, and Fleeson 2004) or positive spillover (Hanson, Hammer, and Colton 2006).

Work-family enhancement can act as a support mechanism to buffer or moderate the conflict workers' experience in their work and family lives by 
eradicating threatening work and family conflicts and making them nonthreatening. In line with Clark's (2000) Border Theory, the concept of work-family enhancement is commonly associated with weak work-family borders, characterized by ones high in permeability and flexibility and that allows blending. In this instance, individuals' participation in both work and family roles (also termed border-crossers; Clark 2000) provides them with more opportunities and resources that could be utilized to enhance functioning in other aspects of their life. Success at work may spillover onto the home, thereby benefiting family relationships and influencing an individual's quality of life. For example, a construction worker may apply conflict management strategies learned at work (i.e., accommodation or collaboration, compromising) to better manage arguments that break out between family members at home. Research in workfamily enhancement also suggests that individuals who are more satisfied with their work tend to experiences less family stress and increased well-being (Barnett, Marshall, and Sayer 1992). Similarly, work-family enhancement can also increase individuals' mental health (Grzywacz and Marks 2000), job and family satisfactions (McNall, Nicklin, and Masuda 2009; Pinquart and Sörensen 2000). Satisfaction in work and family domains, in turn, will also have additive effects on an individual's life satisfaction (Rice, Frone, and Mcfarlin 1992).

A limitation of past research on work-family enhancement is that researchers only tested a simple main effect relationship, treating conflict and enhancement as independent variables (IVs). Only two studies in this area attempted to examine the interaction effect between conflict and enhancement based on the same panel data - the National Survey of Midlife Development in the United States. Grzywacz and Bass (2003) found a significant interaction between workfamily enhancement and conflict on anxiety disorder, while Gareis et al. (2009) found a significant interaction between work-family enhancement and conflict on relationship quality. Despite these important findings, to our knowledge, no other studies have examined the buffering effects of work-family enhancement on work-family conflict in relation to SBOs and their well-being. Moreover, studies such as Grzywacz and Bass (2003) and Gareis et al. (2009) did not concurrently examine both types of well-being (subjective and psychological).

Similar to previous literature, we argue that work-family enhancement may buffer the negative effects of work-family conflict on SBOs' well-being. When SBOs feel that their work practices are inhibiting them from attending family responsibilities, having access to work-family enhancement can act as a personal resource that will mitigate these negative experiences. That is, being an owner, SBOs may be required to work long hours and thus have less time for personal life or family activities (work-family conflict). However, successful SBOs may apply time management and organization skills learned at work to 
better manage their personal and family time, and, as a result can better balance their work and family responsibilities (work-family enhancement). Therefore, work-family enhancement can be viewed as a support mechanism that helps moderate the conflict SBOs experienced in their work and family lives by eradicating threatening work and family conflicts and making them nonthreatening. Accordingly, we hypothesize that:

Hypothesis 2: Under conditions of high work-family conflict rather than low, work-family enhancement will moderate the negative effect between work-family conflict and SBOs' levels of subjective well-being [i.e., job satisfaction (H2a), family satisfaction (H2b), life satisfaction (H2c)] and psychological well-being [mental health (H2d)].

\section{Social Support}

In line with research in the work-family interface (Greenhaus and Powell 2006) and Clark's (2000) Border Theory, stress models have also considered social support to be an important resource that can buffer the negative effects that work-family conflict has on individuals' well-being (Frone, Russell, and Cooper 1992; Michel et al. 2010). Social support is defined as the availability of people (e.g., family members or colleagues) on whom an individual can rely for physical, emotional, instrumental, informational and social aid (Michel et al. 2010).

According to Border Theory, the support from influential individuals (i.e., border-keepers) in border-crossers' lives (e.g., SBOs) can buffer the negative effects of work-family conflict (Clark 2000). Previous researchers also support this notion by postulating that nonwork-related social support from influential family members can also reduce work-family conflict (Wadsworth and Owens 2007). For example, given the pivotal role of spouses in an individual's decision-making process and family lives, having a supportive spouse who sympathizes with SBOs' flexible work patterns may reduce arguments and, in turn, work-family conflict (Wadsworth and Owens 2007). In addition to nonwork-related social support, the degree of social support individuals receive from work may also reduce their work-family conflict (Carlson and Perrewé 1999). When individuals are experiencing conflict arising from their job, having access to support from work peers can greatly mitigate the negative effects of the conflict felt (i.e., work-related social support; Carlson and Perrewé 1999). Aligning with the above studies, it is imperative to consider both work-related and nonwork-related sources of social support that individuals may have access to. 
Work-related social support is derived from work domains and refers to the support that individuals' colleagues, and broader organizations in which they are embedded provide to them in order to help facilitate a more positive working environment (Michel et al. 2010). According to the meta-analysis by Kossek et al. (2011), this type of social support can increase job satisfaction and moderate the negative impacts work-family conflict has on individuals' well-being. For example, in similar work conditions, workers who receive more assistance and support from their colleagues often report having lower work-family conflict (Kossek et al. 2011).

In the context of SBOs, social support, which is derived from work domain, can refer to members from related business network, business mentors or local community (Stuart and Sorenson 2005). The relationship between community support and small business success has been highlighted in many studies (e.g., Besser 1999; Kilkenny, Nalbarte, and Besser 1999). Having a supportive working environment can contribute to a supportive organizational network, which, in turn, increases job satisfaction and well-being (Kossek et al. 2011). Nonworkrelated social support refers to the support provided by family, spouse and peers from an individual's nonwork domains (Kossek et al. 2011). Much like workrelated social support, nonwork-related social support has been found to reduce work-family conflict. More specifically, a supportive relationship with one's spouse is associated with decreased work-family conflict in married couples (Halbesleben, Wheeler, and Rossi 2012). For example, men tend to report higher job satisfaction when their wives support their work choices. Halbesleben, Wheeler, and Rossi (2012) further note that a supportive and understanding spouse is less likely to become upset when work demands interfere with family demands, thereby reducing work-family conflicts.

While previous studies have argued that social support is the moderating variable that influences the strength and direction of the relationship between work-family conflict and well-being, the evidence from these studies has generally been inconclusive (Carlson and Perrewé 1999). The three studies that specifically examined the moderating role of social support on work and family domains have also found mixed results. Studies by Phelan et al. (1991) and Frone, Russell, and Cooper (1992) both found that social support did not significantly moderate the effect work-family conflict has on workers' levels of depression. In contrast, Parasuraman, Greenhaus, and Granrose (1992) found that social support had a small but significant moderating effect on the relationship between work-family conflict and psychological well-being. Finally, a recent meta-analysis by Kossek et al. (2011) argued that social support has a strong relationship with work-family conflict. Finally the aforementioned studies all utilized cross-section correlational data, and as a result, were unable to 
draw casual inferences. As suggested by Frone, Russell, and Cooper (1992), a cross-wave data would allow for stronger casual inferences. Given the lack of agreement and limitations in the literature, in our study, we aim to utilize a time lag design to validate the moderating role of social support in relation to workfamily conflict. Accordingly, we hypothesize that:

Hypothesis 3: Under conditions of high work-family conflict rather than low, social support will moderate the negative effect between work-family conflict and SBOs' levels of subjective well-being [i.e., job satisfaction (H3a), family satisfaction (H3b), life satisfaction (H3c)] and psychological well-being [mental health (H3d)].

\section{Methodology}

\section{Participants and Procedure}

The participants in the current study are limited to SBOs. In line with the Australian Bureau of Statistics, small businesses are defined as having fewer than 20 people. This definition will also include nonemploying and microbusinesses (DIISR 2012). The sample of SBOs was drawn from The Household Income and Labour Dynamics in Australia (HILDA) survey ${ }^{1}$. The initial sample of households was selected using a multistage approach. (Refer to the HILDA manual for more details regarding the sampling methodology (Summerfield et al. 2011).) The HILDA survey is designed to gather basic information about the composition of the household as well as attitudinal questions. Given the complexity of these instruments, the HILDA survey thus provides enriching information to researchers, government officials and social welfare agencies to assist them in making better decisions to benefit the Australian population.

The present study utilized data collected at two time points over a two-year period from 2010 to 2011 (Wave 10-Wave 11). The analysis sample contains participants who have participated in the HILDA since wave 10 and have had no changes to the composition of their original households during the period covered by Waves 10-11. As we were interested in the impact of work on family context of SBOs, our sample was restricted to SBOs who are married and have at least one child (dependent child classified as being under 14 years old) in their household, totaling 167 SBOs. Of these participants, there were 102 males (61\%) and 65 females

1 A project initiated and funded by the Australian Government Department of Social Services and managed by the Melbourne Institute of Applied Economic and Social Research, University of Melbourne. 
Table 1: Demographic and descriptive statistics for wave 10.

\begin{tabular}{|c|c|c|}
\hline Demographic variables & Frequency & $\%$ \\
\hline \multicolumn{3}{|c|}{ Number of children under the age of 14 living at home } \\
\hline One child & 32 & 19 \\
\hline Two children & 65 & 39 \\
\hline Three children & 49 & 29 \\
\hline Four or more children & 21 & 13 \\
\hline \multicolumn{3}{|l|}{ Education } \\
\hline High school & 55 & 33 \\
\hline $\begin{array}{l}\text { Certificate III, IV or advanced } \\
\text { diploma }\end{array}$ & 75 & 45 \\
\hline Bachelor or honors degree & 22 & 13 \\
\hline $\begin{array}{l}\text { Graduate degree (graduate } \\
\text { diploma or certificate) }\end{array}$ & 7 & 4 \\
\hline $\begin{array}{l}\text { Postgraduate degree (masters, } \\
\text { PhD or doctorate) }\end{array}$ & 8 & 5 \\
\hline \multicolumn{3}{|l|}{ Occupational tenure } \\
\hline $1-10$ years & 74 & 45 \\
\hline $11-20$ years & 50 & 30 \\
\hline 20 or more years & 42 & 25 \\
\hline \multicolumn{3}{|l|}{ Business income } \\
\hline Under $\$ 10,000$ & 54 & 32 \\
\hline$\$ 10,000-\$ 30,000$ & 50 & 30 \\
\hline$\$ 31,000-\$ 50,000$ & 24 & 14 \\
\hline$\$ 51,000-\$ 100,000$ & 16 & 10 \\
\hline Over $\$ 100,000$ & 7 & 4 \\
\hline Did not answer & 16 & 10 \\
\hline
\end{tabular}

(39\%), aged from 23 to 66 years ( $M_{\text {age }}=42$ years, $\mathrm{SD}=7.71$ ). Participants' highest education levels varied, with most having completed a certificate or diploma and all are currently working full-time. Average occupational tenure is 13 years, and the average business income after tax is $\$ 32,996$. Demographic variables of the participants at wave 10 are presented in Table 1.

\section{Measures}

\section{Control Variables}

Based on previous empirical studies, individuals' subjective and psychological well-being is not only contingent on work-family conflict, enhancement and 
social support, but also on their occupational tenure and business income (Gudmunson et al. 2009). Similarly, Adkins et al. (2013) found that women business owners' desire for work-life balance generally leads to a more positive work-family culture within their organization. Similarly, Gudmunson et al. (2009) also suggest that, female SBOs tend to suffer from more liabilities associated with income, size and newness in comparison to male SBOs. In response to these findings, gender, occupational tenure and business income were controlled. Because SBOs' family lives can also influence their business and experiences of work-family conflict (Baron 2004; Jennings and McDougald 2007), marital status and number of children under 14 years old were controlled. We also included age and highest education level as control variables because research has shown that these variables may influence an individual's workfamily experiences (Barnett and Hyde 2001; Chen, Powell, and Greenhaus 2009). These variables were included to rule out the possibility of alternative explanations when finding significant relationships between our study's focal variables.

\section{Independent Variable}

\section{Work-Family Conflict}

We assessed work-to-family conflict/interference at wave 10 with a three-item scale adapted from Marshall and Barnett (1993). Participants rated their answers a 7-point Likert scale ranging from 1 (strongly disagree) to 7 (strongly agree), with high scores indicating greater work-family conflict. Sample items are "Because of the requirements of my job, I miss out on home or family activities that I would prefer to participate in" and "Working causes me to miss out of some of the rewarding aspects of being a parent.” Refer to Appendix A.1 for the full list of questionnaire items. Reliability analysis indicated that this scale was reliable $(\alpha=0.87)$.

\section{Potential Moderating Variables}

\section{Work-Family Enhancement}

Work-to-family enhancement was assessed at wave 10 using a five-item scale adapted from Marshall and Barnett (1993). Participants rated their agreement with each of the five items on a 7-point Likert scale ranging from 1 (strongly disagree) to 7 (strongly agree), with high scores indicating greater work-family enhancement. Sample items are "My work has a positive effect on my children" and "Working 
makes me feel good about myself, which is good for my children." Refer to Appendix A.2 for the full list of questionnaire items. Reliability analysis indicated that this scale was reliable at measuring work-family enhancement $(\alpha=0.84$ ).

\section{Social Support}

For the purpose of our study, we will utilize the term "social support" as a global term that incorporates both work-related and nonwork-related social support. Following Kossek et al. (2011), a global measure of social support was used to capture all the possible sources of support available to SBOs. Accordingly, social support was assessed at wave 10 using six items adapted from Henderson et al. (1978), to reflect the overall support that SBOs receive from their social (workand nonwork-related) networks. Sample items are "I often need help from other people but can't get it" (reverse coded) and "I seem to have a lot of friends." Participants were asked to rate the extent of their agreement with these items on a 7-point Likert scale ranging from 1 (strongly disagree) to 7 (strongly agree), with higher scores indicating greater amounts of social supported received. Refer to Appendix A.3 for all questionnaire items. Reliability analysis of this scale indicated that it had strong reliability $(\alpha=0.80)$.

\section{Dependent Variables}

The DVs were mental health (psychological well-being), job satisfaction, family satisfaction and life satisfaction (subjective well-being).

\section{Psychological Well-Being}

Psychological well-being was assessed at wave 11 using a nine-item subscale adopted from the SF-36 health survey (Ware et al. 2002). Participants were asked to score their positive mental health conditions on a 6-point rating scale ranging from 0 (all of the time) to 100 (none of the time), with higher scores indicating greater psychological well-being. Sample items are "Have you felt so down in the dumps that nothing could cheer you up?" (reverse coded) and "Have you been a happy person?” Previous studies have indicated that the SF-36 and all it subscales have good psychometric properties (Cole, Daly, and Mak 2009; Summerfield et al. 2011). Refer to Appendix A.4 for all questionnaire items. Reliability analysis indicated that this scale was reliable for measuring psychological well-being ( $\alpha=0.88$ ). 


\section{Subjective Well-Being}

We assessed subjective well-being based on three measures of job satisfaction, family satisfaction and life satisfaction at wave 11 .

\section{Job Satisfaction}

Job satisfaction was six items adapted from the British Household Panel Survey (Taylor et al. 2010). Participants were asked to score their satisfaction of their current job on a 10-point rating scale ranging from 0 (very dissatisfied) to 10 (very satisfied), with high scores indicating greater job satisfaction. A sample item is "How satisfied are you with the hours you work?” Refer to Appendix A.5 for all questionnaire items. Reliability analysis indicated that this scale had strong reliability for measuring job satisfaction $(\alpha=0.79)$.

\section{Family Satisfaction}

Family satisfaction was assessed using an eight-item scale adapted from the Australian Living Standards Study (McDonald and Brownlee 1993). Participants were asked to score their satisfaction of their family members and circumstances on a 10-point rating scale ranging from 0 (very dissatisfied) to 10 (very satisfied), with high scores indicating greater family satisfaction. A sample item is "How satisfied are you with your relationship with your partner?" Refer to Appendix A.6 for all questionnaire items. Reliability analysis indicated that this scale had strong reliability $(\alpha=0.81)$.

\section{Life Satisfaction}

Life satisfaction was measured with a nine-item questionnaire adapted from Cummins (1996). Responses are given based on a 10-point rating scale ranging from 0 (very dissatisfied) to 10 (very satisfied), with high scores indicating greater life satisfaction. Example items are: "How satisfied are you with your life?" and "How satisfied are you with the amount of free time you have?" Refer to Appendix A.7 for all questionnaire items. Reliability analysis indicated that this scale was reliable at measuring life satisfaction $(\alpha=0.79)$.

\section{Analyses}

In line with empirical research, our unit of analysis is SBOs (De Bruin and Dupuis 2004; Dyer 2003; Jennings and McDougald 2007). In the preliminary 
stage, correlation analyses were used to test the strength of the relationship between the IV (work-family conflict), the moderating variables (work-family enhancement and social support) and DVs (job, family, life satisfaction and mental health). To test the proposed hypotheses, moderation models and accompanied hierarchical multiple regression analyses were conducted. These analyses examined the hypothesized effects of work-family conflict (H1) and moderating effects of work-family enhancement (H2) and social support (H3). It was expected that the DVs would be affected by the IVs, with some moderation relationships occurring.

We used hierarchical multiple regression method because our sample size is relatively small for an SEM method (Klein 2011). Yet, a priori G*Power 3.1 analysis (a stand-alone power analysis program) for linear multiple regression, fixed model, $R^{2}$ increase (Faul et al. 2009) indicated that for power of 0.80 and alpha level of 0.05 , a sample of approximately 77 participants was required to reach a medium effect size $\left(f^{2}=0.15\right)$. Therefore, the traditional regression is deemed to be appropriate method due to our sample size limitation.

Heaney, Israel, and House (1994) suggest that it may take approximately a year before individuals' experiences of job stressors (e.g., work-family conflict) are reflected in impaired well-being. Accordingly, we aim to examine the impact of our first-wave IVs on well-being 12 months later. Nonetheless, we also ran additional tests to examine the impact of IVs and DVs within the same wave, as well as cross-wave. Our expectation of these results would be that IVs influence DVs both within-wave and cross-wave analysis, but cross-wave results demonstrate stronger impact (due to the time lag between stressors and outcome as mentioned earlier).

\section{Results}

\section{Descriptive Statistics}

Table 2 displays the means, standard deviation, standard errors of the mean, 95\% confidence intervals and range statistics for focal variables of the present study.

\section{Construct Validity}

An exploratory factor analysis was conducted to assess the construct validity of the independent measures. No assumptions were violated unless specified 
Table 2: Descriptive statistics for work-family conflict, enhancement, social support, subjective and psychological well-being in waves 10 and 11.

\begin{tabular}{|c|c|c|c|c|c|c|c|c|c|}
\hline \multirow[t]{2}{*}{ Variable } & \multirow[t]{2}{*}{$N$} & \multirow[t]{2}{*}{$M$} & \multirow[t]{2}{*}{$S D$} & \multirow[t]{2}{*}{$S E$} & \multicolumn{2}{|r|}{$95 \% \mathrm{Cl}$} & \multirow[t]{2}{*}{ Range } & \multirow[t]{2}{*}{ Skewness } & \multirow[t]{2}{*}{ Kurtosis } \\
\hline & & & & & Lower & Upper & & & \\
\hline $\begin{array}{l}\text { Work-family } \\
\text { conflict } \\
\text { (wave 10) }\end{array}$ & 163 & 3.62 & 1.48 & 0.12 & 3.39 & 3.85 & $1.00-7.00$ & -0.09 & -0.66 \\
\hline $\begin{array}{l}\text { Work-family } \\
\text { enhancement } \\
\text { (wave 10) }\end{array}$ & 159 & 4.92 & 0.95 & 0.08 & 4.77 & 5.65 & $2.20-7.00$ & -0.08 & 0.08 \\
\hline $\begin{array}{l}\text { Social support } \\
\text { (wave 10) }\end{array}$ & 150 & 5.30 & 1.06 & 0.09 & 5.13 & 5.48 & $2.50-7.00$ & -0.46 & -0.54 \\
\hline $\begin{array}{l}\text { Job satisfaction } \\
\text { (wave 11) }\end{array}$ & 167 & 7.34 & 1.31 & 0.10 & 7.35 & 7.55 & $2.83-10.00$ & -0.78 & 0.82 \\
\hline $\begin{array}{l}\text { Family } \\
\text { satisfaction } \\
\text { (wave 11) }\end{array}$ & 167 & 6.50 & 1.57 & 0.12 & 6.26 & 6.74 & $1.82-10.00$ & -0.69 & 0.45 \\
\hline $\begin{array}{l}\text { Life satisfaction } \\
\quad \text { (wave 11) }\end{array}$ & 167 & 7.24 & 1.06 & 0.08 & 7.08 & 7.40 & $3.78-10.00$ & -0.39 & 0.65 \\
\hline $\begin{array}{l}\text { Mental health } \\
\text { (wave 11) }\end{array}$ & 167 & 76.23 & 15.32 & 1.18 & 73.87 & 78.54 & $32.00-100$ & -0.94 & 0.20 \\
\hline
\end{tabular}

Note: $S D=$ Standard Deviation; $S E=$ Standard Error; $\mathrm{Cl}=$ Confidence Intervals for Mean.

otherwise. Accordingly, a principal component analysis as suggested by Tabachnick and Fidell (2007) with Varimax rotation was conducted on the 14 items of the work-family conflict, work-family enhancement and social support to examine their underlying structures.

Three factors (with eigenvalues exceeding 1.0) were identified and together explained $50.56 \%$ of the variance in the data. The first factor (labeled "workfamily conflict") explained $25.30 \%$ of the variance ( $n=3$ items), the second factor (labeled "work-family enhancement") $14.79 \%$ of the variance ( $n=5$ items) and the third factor (labeled "social support") $10.47 \%$ of the variance ( $n=6$ items). All independent construct items loaded unidimensionally on one factor and had no significant cross-loadings with other factors. Cross-loadings were all well below the cut-off of 0.40 as suggested by Field (2013) and factor loadings were all above 0.49 , which is considered a good loading. The factor loading matrix is presented in Table 3. The factor analysis results thus demonstrated that work-family conflict, work-family enhancement and social support were three separated constructs. In order to further demonstrate the discriminant validity for work-family conflict and work-family enhancement, we 
Table 3: Pattern matrix for principal factor analysis with Varimax rotation for work-family conflict, enhancement and social support measures.

\begin{tabular}{|c|c|c|c|}
\hline \multirow[t]{2}{*}{ Items } & \multicolumn{3}{|c|}{ Pattern loading } \\
\hline & $\begin{array}{r}\text { Work-family } \\
\text { conflict }\end{array}$ & $\begin{array}{r}\text { Work-family } \\
\text { enhancement }\end{array}$ & $\begin{array}{r}\text { Socia } \\
\text { support }\end{array}$ \\
\hline $\begin{array}{l}\text { Because of the requirements } \\
\text { of my job, my family time } \\
\text { is less enjoyable and more } \\
\text { pressured. }\end{array}$ & 0.67 & & \\
\hline $\begin{array}{l}\text { Working leaves me with too } \\
\text { little time or energy to be } \\
\text { the kind of parent I want } \\
\text { to be. }\end{array}$ & 0.77 & & \\
\hline $\begin{array}{l}\text { Working causes me to miss } \\
\text { out on some of the } \\
\text { rewarding aspects of being } \\
\text { a parent. }\end{array}$ & 0.78 & & \\
\hline $\begin{array}{l}\text { Having both work and family } \\
\text { responsibility challenges } \\
\text { me to be the best I can be }\end{array}$ & & 0.49 & \\
\hline $\begin{array}{l}\text { Working makes me feel good } \\
\text { about myself, which is } \\
\text { good for my children }\end{array}$ & & 0.68 & \\
\hline $\begin{array}{l}\text { My work has a positive effect } \\
\text { on my children }\end{array}$ & & 0.55 & \\
\hline $\begin{array}{l}\text { Working helps me better } \\
\text { appreciate the time I } \\
\text { spend with my children }\end{array}$ & & 0.65 & \\
\hline $\begin{array}{l}\text { The fact that I am working } \\
\text { makes me a better parent }\end{array}$ & & 0.72 & \\
\hline $\begin{array}{l}\text { People don't come to visit me } \\
\text { as often as I would like }\end{array}$ & & & 0.62 \\
\hline $\begin{array}{l}\text { I often need help from other } \\
\text { people but I can't get it }\end{array}$ & & & 0.67 \\
\hline I seem to have a lot of friends & & & 0.56 \\
\hline $\begin{array}{l}\text { I don't have anyone that I can } \\
\text { confide in }\end{array}$ & & & 0.81 \\
\hline $\begin{array}{l}\text { I have no one to lean on in } \\
\text { times of trouble }\end{array}$ & & & 0.82 \\
\hline I often feel very lonely & & & 0.68 \\
\hline Percentage of variance & $25.30 \%$ & $14.79 \%$ & $10.47 \%$ \\
\hline
\end{tabular}

Note: Extraction method: principal axis factoring; rotation method: Varimax with Kaiser normalization; factor loadings $<0.2$ are suppressed. 
calculate the extent to which the two scales overlap by using the following formula where $r_{x y}$ is correlation between $x$ and $y, r_{x x}$ is the reliability of $x$, and $r_{y y}$ is the reliability of $y$ (John and Benet-Martinez 2000). If the result is less than 0.85 it means discriminant validity likely exists between the two scales. Based on this formula, we obtained 0.2; therefore, we can conclude that the two scales measure theoretically different constructs.

\section{Statistical Analysis}

Bivariate correlations were conducted to examine the strength of the relationships between predictors and the outcome variables (Field 2013). Table 4 displays the bivariate correlations and Cronbach's alpha reliability statistics for the work-family conflict, enhancement, social support, measures of subjective (job, family, life satisfactions) and psychological well-being (mental health). The Cronbach's alphas revealed that all measures had good internal consistencies (i.e., ranging from 0.79 to 0.88; see Tabachnick and Fidell 2007).

In line with previous literature (Aryee, Srinivas, and Tan 2005; Ford, Heinen, and Langkamer 2007; Pinquart and Sörensen 2000), in the present study, we expected a negative relationship between work-family conflict and SBOs' subjective and psychological well-being. In contrast, work-family enhancement and social support should have a positive relationship with both types of well-being. On visual inspections of these data in Table 4, it can be seen that all the correlations between work-family conflict and life, family, job satisfactions (subjective well-being) and mental health (psychological well-being) were all significant and in the predicted direction. Additionally, work-family enhancement significantly correlated with measures of subjective well-being but not

Table 4: Pearson correlations and Cronbach's alphas for focal variables $(N=167)$.

\begin{tabular}{lrrrrrrr}
\hline Variables & $\mathbf{1}$ & $\mathbf{2}$ & $\mathbf{3}$ & $\mathbf{4}$ & $\mathbf{5}$ & $\mathbf{6}$ & $\mathbf{7}$ \\
\hline 1. Work-family conflict & $(0.8)$ & $-0.39^{*}$ & $-0.33^{*}$ & $-0.20^{\star}$ & $-0.31^{\star}$ & $-0.32^{\star}$ & -0.15 \\
2. Work-family enhancement & & $(0.84)$ & 0.07 & $0.29^{\star}$ & $0.25^{\star}$ & $0.29^{\star}$ & 0.13 \\
3. Social support & & & $(0.80)$ & $0.36^{\star}$ & $0.39^{\star}$ & $0.28^{\star}$ & $0.37^{\star}$ \\
4. Life satisfaction & & & & $(0.79)$ & $0.40^{\star}$ & $0.59^{\star}$ & $0.45^{\star}$ \\
5. Family satisfaction & & & & & $(0.81)$ & $0.34^{\star}$ & $0.28^{\star}$ \\
6. Job satisfaction & & & & & & $(0.79)$ & $0.22^{\star}$ \\
7. Mental health & & & & & & & $(0.88)$ \\
\hline
\end{tabular}

Note: ${ }^{\star} p<0.01$. Cronbach's alphas (internal reliabilities) are in the diagonals. 
psychological well-being while social support significantly correlated with both types of well-being. While causality cannot be established, these correlations suggest that the negative effects of work-family conflict experienced by SBOs are related to reductions in their subjective and psychological well-being. In contrast, work-family enhancement is associated with a positive subjective wellbeing. Similarly social support was demonstrated to have a positive relation with both measures of well-being. Although the work-family constructs did not significantly correlate with psychological well-being directly, the correlation coefficients show that psychological well-being was positively and significantly correlated with SBOs' subjective well-being. Correlations also indicated that multicollinearity issues were not present among variables.

\section{Hypotheses Testing}

To test the three hypotheses, a series of hierarchical multiple regression analyses were conducted with measures of subjective and psychological well-being as the outcome variables. To reduce potential multicollinearity problems, the IVs (predictor and moderators) were centered before being added into regression equations (Aiken, West, and Reno 1991). In the first step, gender, age, marital status, education, occupational tenure and business income were entered into the hierarchical multiple regressions as control variables. To test the main effect of the predictors on criterion variables after controlling for the influence of confounding variables, work-family conflict, work-family enhancement and social support were entered at step two. Finally, the two possible two-way interaction terms (work-family conflict $\times$ work-family enhancement; work-family conflict $\times$ social support) were added in step three. These interaction terms were calculated from the centered versions of the independent and moderating variables (Aiken, West, and Reno 1991). Results of the hierarchical multiple regression analyses are displayed in Table 5 .

Hypothesis 1 proposed that work-family conflict would be negatively associated with job, family, life satisfaction (subjective well-being) and mental health (psychological well-being), respectively. Table 5 shows that none of the set of control variables accounted for a significant variability in SBOs' subjective and psychological well-being. The addition of work-family conflict and enhancement in the second step explained an incremental variance over and above the control variables for job $\left(\Delta R^{2}=0.17 ; \Delta F(1,121)=15.09, p<0.01\right)$, family $\left(\Delta R^{2}=0.17\right.$; $\Delta F(1,121)=17.23, p<0.01)$, life $\left(\Delta R^{2}=0.09 ; \Delta F(1,121)=7.46, p<0.01\right)$ satisfactions (subjective well-being) and mental health $\left(\Delta R^{2}=0.08\right.$; 


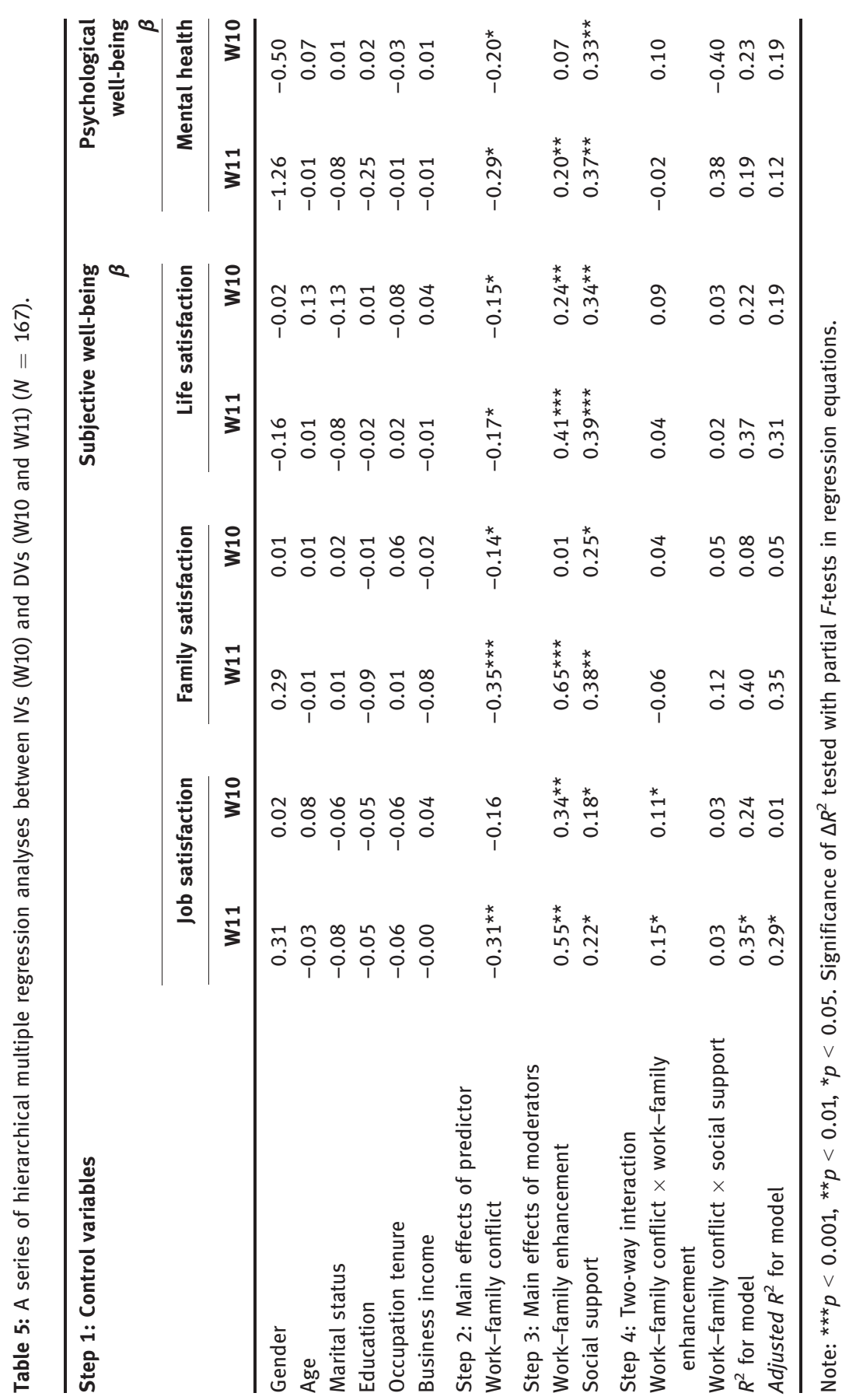


$\Delta F(1,121)=6.75, p<0.01)$. Further, in the expected direction, work-family conflict negatively influenced job $(\beta=-0.31, p<0.01)$, family $(\beta=-0.35, p<$ $0.001)$, life $(\beta=-0.17, p<0.05)$ satisfactions and mental health $(\beta=-2.31, p$ $<0.05$ ). As work-family conflict increases, SBOs' subjective and psychological well-being decreases. Therefore, hypothesis 1 was fully supported.

Hypothesis 2 proposed that work-family enhancement would moderate the relationship between work-family conflict and well-being. Table 5 shows that the set of control variables did not account for a significant variability in wellbeing. Work-family enhancement also positively and significantly influenced SBOs' job $(\beta=0.55, p<0.01)$, family $(\beta=0.65, p<0.001)$ and life $(\beta=0.41$, $p<0.001)$ satisfactions but not mental health $(\beta=1.65$, ns). Additionally, the interaction term for work-family conflict $\times$ work-family enhancement added a significant increment in variance over and above that explained by the control variables and main effects $\left(\Delta R^{2}=0.35 ; \Delta F(2,117)=3.04, p<0.05\right)$. This interaction term also had a positive and statistically significant coefficient predicting job satisfaction $(\beta=0.15, p<0.05)$, suggesting that the relationship between work-family conflict and SBOs' job satisfaction differs depending on the level of their work-family enhancement.

To further examine this moderating effect, simple slope analyses were conducted. The interaction term was plotted using standardized regression coefficients at one standard deviation above and below the mean (see Aiken, West, and Reno 1991), which is graphically represented in Figure 2. As can be seen in Figure 2, work-family conflict was negatively related to job satisfaction among SBOs

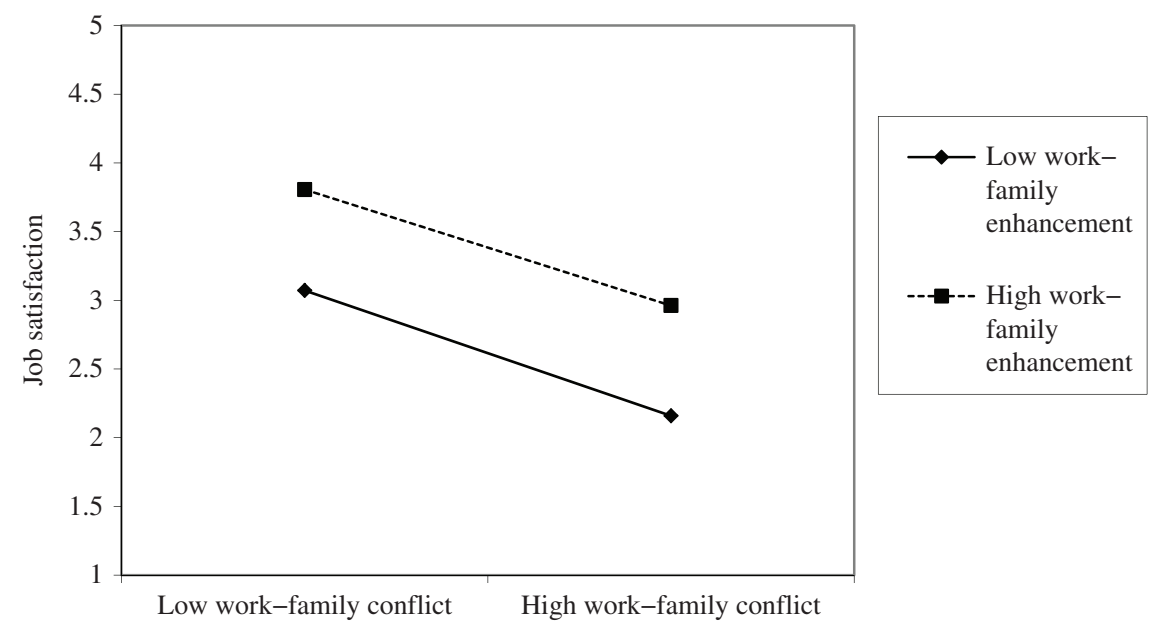

Figure 2: Interaction between work-family conflict and enhancement on job satisfaction. 
reporting low work-family enhancement (simple slope test: $t=-2.90, p<0.05$ ), whereas at high levels of work-family enhancement, the effect of work-family conflict was less prominent $(t=-1.15, p<0.05)$. Finally, the interaction term for work-family conflict $\times$ work-family enhancement did not significantly predict family satisfaction, life satisfaction and mental health. Thus, these findings provide support for hypothesis 2 regarding job satisfaction, suggesting that work-family enhancement buffers the negative effects of work-family conflict on job satisfaction. From these findings, hypothesis 2 is partially supported.

Hypothesis 3 proposed that social support would moderate the relationship between work-family conflict and well-being. As shown in Table 5, the set of control variables did not significantly account for a proportion of variability in SBOs' subjective and psychological well-being. When work-family conflict and social support were entered, they together accounted for a significant proportion of variability in SBOs' job $\left(\Delta R^{2}=0.32 ; \Delta F(2,119)=12.89, p<0.001\right)$, family $\left(\Delta R^{2}=0.39 ; \Delta F(2,119)=20.91, p<0.001\right)$, life $\left(\Delta R^{2}=0.36 ; \Delta F(2,119)=24.67\right.$, $p<0.001)$ satisfactions (subjective well-being) and mental health $\left(\Delta R^{2}=0.19\right.$; $\Delta F(2,119)=9.45, p<0.001)$ (psychological well-being). Further, in the expected direction, social support positively influenced job $(\beta=0.22, p<0.05)$, family $(\beta=0.38, p<0.01)$, life $(\beta=0.39, p<0.001)$ satisfactions and mental health $(\beta=4.93, p<0.01)$. This suggests that as social support increases, SBOs' subjective and psychological well-being also increases. While main effects were present, the interaction term between work-family conflict and social support was found to be nonsignificant, meaning that the relationship between work-family conflict and SBOs' subjective and psychological well-being did not differ depending on their level of social support. Consequently, hypothesis 3 is not supported.

Supplementary tests were performed to examine the impact of IVs and DVs within the same wave (see Table 5). The results showed that work-family conflict influenced on family satisfaction, life satisfaction and mental health. Likewise, work-family enhancement influenced on job satisfaction, life satisfaction and mental health. Social support influenced on all DVs. However, the relationships were weaker than the cross-wave. We also ran additional regressions by controlling first-wave IVs, the outcomes of relationships yield the same patter with initial cross-wave analyses.

\section{Discussion}

Our study responded to calls for theory and research on work-family aspects in entrepreneurship research, examining work-family interaction and well-being among SBOs. Despite the extensive evidence base for the effects work and family 
interactions have on well-being, researchers have not focused on SBOs (e.g., Dyer 2003; Jennings and McDougald 2007). Further, our study contributed to small business and entrepreneurship research, which heavily focuses on economic outcomes, by focusing on intangible outcomes, i.e., psychological wellbeing. Our results extended the existing knowledge of relationship among conflict and enhancement of work-family interface as outlined below. The next section explains the relationship of each key variables (i.e., conflict, enhancement and social support) and how these variables impact on well-being.

\section{Work-to-Family Conflict/Interference}

Increasingly concerns have been raised about the effect of high job demands negatively affecting the home domain (Grzywacz and Bass 2003; Maertz and Boyar 2011). While numerous past research has examined the effects workfamily conflict has on organizationally employed individuals, few have utilized SBO samples. Accordingly, the present study aims to examine the relationship between work-family conflict and well-being of SBOs (Jennings and McDougald 2007; Powell and Eddleston 2013). Based on theory and research on work-family conflict and well-being in the literature (Aryee, Srinivas, and Tan 2005; Ford, Heinen, and Langkamer 2007), it was hypothesized that work-family conflict would have a negative impact on SBOs' subjective and psychological well-being (H1). In line with prior research (Butler et al. 2005), the current study found, after controlling for confounding variables, that work-family conflict significantly and negatively influenced subjective well-being (life, family and job satisfactions) and psychological well-being (mental health).

The observed relationships between work-family conflict and the two types of well-being measures are consistent with Border Theory which postulates that work-family conflict and work/life dissatisfaction may occur when individuals cannot balance demands from their work and family domains (Clark 2000). Our findings are also consistent with role theory. Underlying role theory is the idea that individuals have a limited amount of attention and time (Greenhaus and Beutell 1985). Therefore, the participation in multiple roles (e.g., work and family), if not managed properly, could swiftly drain an individual's physical and psychological resources (Greenhaus and Beutell 1985). In support of Greenhaus and Beutell (1985), Boyar and Mosley (2007) suggested that the depletion of resources can become overwhelming and result in detrimental consequences to individuals' well-being. In line with these findings, the present study found that SBOs who experience inter-role conflict between work and family experience decreased well-being. 
While the nature of being SBOs is flexible and autonomous (Marjan et al. 2011), there is a trade-off between advantages and disadvantages of the work and family experiences that they face. Research suggests that, while SBOs enjoy greater autonomy and flexibility, they are also more susceptible to psychological strain caused by excessive involvement in their work, which is necessary for the survival of their company (Chen, Powell, and Greenhaus 2009; Parasuraman and Simmers 2001). High amounts of work involvement can thus interfere with parental demands and, in turn, cause role conflict and insurmountable pressures that are not easily resolved by autonomy and flexibility (Pinquart and Sörensen 2000). Consequently, SBOs will experience greater work-family conflict and reduced well-being. Accordingly, the present study underscores the importance of research into identifying factors that reduce the impacts of workfamily conflict on SBOs' subjective and psychological well-being. While previous research has provided valuable insight into the impact of work-family conflict, few researchers have systematically examined this concept over an extended period of time using appropriate control variables as the present study has done. Accordingly the present study extends previous research by demonstrating that the negative impacts of work-family conflict on SBOs' well-being occur over a long period of time, and warrant more careful attention.

\section{Moderating Role of Work-Family Enhancement}

The second aim of this study was to examine the moderating role work-family enhancement has on the relations between work-family conflict and well-being. Based on entrepreneurship theory and research on work-family enhancement (Gareis et al. 2009; Grzywacz and Bass 2003) it was hypothesized that the amount of work-family enhancement SBOs received would moderate the relationship between work-family conflict and well-being outcomes, such that they would be more positive in high-conflict situations. The results show that under high level of conflict, even if SBOs perceive greater level of work-family enhancement, it would not lessen the negative impact of the conflict on their family satisfaction, life satisfaction and mental health. This suggests that once aspects of subjective and psychological health are harmed by work-family conflict, the negative consequence of it would be unchanged. These findings thus emphasize the important issues of work-family conflict and well-being within this occupation.

While work-family enhancement was not a significant moderator for the aforementioned relationships, it did, however, significantly moderate the consequences work-family conflict has on the job satisfaction of SBOs. That is, the 
access to work-family enhancement can help buffer the negative consequences of work-family conflict for job satisfaction. This finding is consistent with Greenhaus and Powell's (2006) model of the work-family enhancement process and previous research auguring that work-family enhancement is related to positive work attitudes and satisfactions (Gareis et al. 2009; Grzywacz and Bass 2003). A possible explanation as to why work-family enhancement moderated the effects of conflict for job satisfaction could be attributed to the study of Wayne, Musisca, and Fleeson (2004). Research by these authors found the role from which work-family enhancement originated has a stronger buffering effect for various well-being outcomes than the role from which the enhancement was received. For example, when individuals perceive work-to-family enhancement, they attribute good things arising from their work, and because of this attribution, they will generally have a more positive experience with work domains (Wayne, Musisca, and Fleeson 2004).

Aside from supporting Wayne, Musisca, and Fleeson's (2004) findings, results from the present study also supported the social exchange theory (McNall, Nicklin, and Masuda 2009). According to this theory, individuals are more likely to have favorable attitudes toward the domain that they perceived to be the originator of the enhancing resource (McNall, Nicklin, and Masuda 2009). That is, resources generated at work (work-family enhancement) are more likely to be related to work-related outcomes. As the present study examined the workto-family interface, the findings are in line with social exchange theory (McNall, Nicklin, and Masuda 2009) by showing that work-family enhancement had a stronger effect on work-related outcomes such as job satisfaction.

While experiencing enhancement in the work domain may assist SBOs to cope with work-family conflict, they are still exposed to conflicts arising from other aspects of their lives (e.g., family-related conflicts; Powell and Eddleston 2013). This experience may reduce the initial buffering effects of work-family enhancement and offers an explanation as to why it did not significantly moderate the consequences of conflict for SBOs' family satisfaction, life satisfaction and mental health. Likewise, it is also possible that work-family enhancement is not associated with family, life satisfaction and mental health because well-being in these domains does not depend on work-related factors (Powell and Eddleston 2013). Nonetheless, the present study provides insight into existing entrepreneurial and psychology literature by showing that the moderating effects of work-family enhancement may differ depending on the type of conflict that SBOs experience (work-to-family may differ from family-to-work). Future research should advance understanding about this relationship by examining which well-being outcomes work-family enhancement is likely to be associated with and why. 


\section{Moderating Role of Social Support}

Social support has been shown to have a moderating effect on the relationship between work-family conflict and individuals' well-being (Kossek et al. 2011; Parasuraman, Greenhaus, and Granrose 1992). However, evidence for this effect has not been consistently supported in entrepreneur and psychology literature (Frone, Russell, and Cooper 1992; Phelan et al. 1991). Consequently, the final aim of this study is to examine whether social support could moderate the relation between work-family conflict and SBOs' well-being. It was hypothesized that the amount of social support SBOs have access to would moderate the negative effects work-family conflict has on their subjective and psychological wellbeing. In contrast to this prediction, the present study found that social support did not significantly moderate the relationship between work-family conflict and SBOs' subjective and psychological well-being. Nevertheless, consistent with a meta-analysis by Chu, Saucier, and Hafner (2010) social support was found to only have a direct main effect with job, family, life satisfactions and mental health. That is, SBOs who have access to social support are likely to have increased subjective and psychological well-being. These findings suggest that having access to social support can increase SBOs' well-being but this additional benefit would not necessarily decrease the negative consequences of workfamily conflict.

Two possible explanations can be offered as to why no moderating effect was found for social support in this study. Firstly, social support may be beneficial to SBOs' well-being but not necessarily helpful when they are experiencing work-family conflict. Bolger, Zuckerman, and Kessler (2000) proposed that individuals are reluctant to seek support from their networks in times of stress because it is embarrassing and may make others look down on them. Therefore, social support may mitigate the negative relationship between workfamily conflict and well-being only if individuals seek or receive the support in time (Chu, Saucier, and Hafner 2010). Thus, it could be argued that the nonsignificant moderating effect found in the present study is caused by the delaying or lack of social support perceived by respondents at the time of workfamily conflict/stressful event.

The second alternative explanation as to why the findings did not support our hypothesis could be attributed to the type of social support measures. The present study examined global rather than specific forms (work related or nonwork related) of social support. Thus it is possible that specific types of support are differentially related to the relation between work-family conflict and wellbeing outcomes. Frone, Russell, and Cooper (1992) found that work-related 
social support is more likely to moderate the impact of work-to-family conflict. In contrast, nonwork-related social support moderates family-to-work conflict (Carlson and Perrewé 1999; Phelan et al. 1991). Similarly, Beehr et al. (2003) also postulated that the moderating effects of social support are more common when the sources of support and conflict are similar. For example, when conflict arises from the workplace, family members may not fully understand the situation and thus be unable to give effective feedback and support.

Finally, methodological issues surrounding items in the social support questionnaire could also have affected the results. According to Abbey, Abramis, and Caplan (2010), the degree of specificity participants are required to think differs depending on the terminology used in the questionnaire items. For example, terms such as "person" often require individuals to consider only a single source of social support while "people" allows them to consider multiple sources of support (Abbey, Abramis, and Caplan 2010). As the social support questionnaire used in the present study utilized the term "people," respondents may have just considered the more general sources of social support instead of considering each and every support network he or she has access to on a daily basis. Thus, responses are likely to have reflected an assessment of global rather than of specific types and sources of social support. Consequently, the findings regarding the social support may not be an accurate representation of the actual buffering effect it has on SBOs' well-being.

Although the present study did not provide information regarding the buffering mechanisms of social support on the relationship between workfamily conflict and well-being, it does emphasize the importance of examining the main effects of social support on well-being. As noted by Abbey, Abramis, and Caplan (2010), having a clear understanding of the main effects of social support on well-being is crucial in creating interventions to reduce work-family conflict. Thus, it is vital for researchers to not underestimate the important role social support's main effects have on SBOs' well-being.

\section{Strengths, Limitations and Future Research}

The findings from the present study need to be considered within the context of a number of limitations. Firstly, our study is limited by the design. The use of self-report measures is associated with the problem of common method bias and leads to informants inflating their opinion or responses (Podsakoff et al. 2003). However, the use of a cross-wave data allows us to reduce this bias by separately measuring out predictor and outcome variables. The use of a twowave study design also allowed us to reduce the likelihood of inflated 
associations by assessing our moderators and outcome variables at distinct points in times. Moreover, exploratory factor analysis revealed that our study's variables were independent constructs at their respective time points (waves 10 and 11). Lastly, common method bias can only account for bivariate associations and not interaction effects (Podsakoff et al. 2003; Siemsen, Roth, and Oliveira 2009). From our assessment of the correlations in the present study, the absence of both multicollinearity issues and intuitive relationships, we thus believe that it is unlikely that the findings were exclusively caused by common method bias.

Second, our study only examined work-to-family conflict and enhancement and thus was unable to fully capture the dimensionality of the work-family interface. Multiple trends of empirical reports have asserted that work-to-family conflict/enhancement is different from family-to-work conflict/enhancement (Frone, Russell, and Cooper 1992; Frone, Yardley, and Markel 1997; Netemeyer, Boles, and McMurrian 1996). Samples from these studies suggested that the correlation between these concepts are low to moderate, thus supporting the idea that they are distinct concepts $(r=0.30-0.55$; Frone, Russell, and Cooper 1992; Frone, Yardley, and Markel 1997; Netemeyer, Boles, and McMurrian 1996). A recent meta-analysis (Shockley and Singla 2011) of the work-family literature has also highlighted that the effect of conflict and enhancement on well-being is dependent on their direction. While the present study argued that it is more likely for conflict/enhancement to stem from work domains (Daniel and Sonnentag 2014), it would be interesting to also examine how SBOs' family dynamics can interfere or enhance their work lives.

Third, our study identified social support as a moderator in the relationship between work-family conflict and subjective and psychological well-being. However, social support did not attenuate the relationship between the aforementioned relationships. Some other research has shown that different types of social support moderate work-family conflict differently (Kossek et al. 2011). Therefore, future research should aim to identify different types of social support that buffer this relationship. Moreover, other moderators should also be identified. An important moderator could be conflict management skills at the workplace.

Fourth, business characteristics such as industry, number of employees and profitability were not available for this panel data. These variables are common in small business research as it focuses on firm level. Yet, our study aimed to explain personal variables at individual level; therefore, the studied variables were captured at a person level, rather than firm level. Nonetheless, the merit of the present study can be further validated by examining the relationship between individual and firm characteristics in future research. 
Notwithstanding the aforementioned limitations, the present study makes a number of primary contributions to the psychology and entrepreneurial literatures. First, we complement and broaden existing knowledge about the impact of work-family conflict on the subjective and psychological well-being of SBOs. Second, we advance existing knowledge of the buffering effects work-family enhancement and social support have on the relationship between work-family conflict and SBOs' well-being. Finally, unlike previous studies that have used financial measures (such as growth and profitability) to understand SBOs' economic well-being, in line with newer research (Srivastava, Locke, and Bartol 2001), our study utilized SBOs' satisfactions (job, family, life) and psychological functioning (mental health) to measure their subjective and psychological well-being, respectively.

\section{Conclusion and Practical Implications}

The present study contributes to the entrepreneurial and psychology literature by examining the effect work-family conflict, enhancement and social support have on the subjective and psychological well-being of SBOs. Results were generally consistent with previous research, indicating that work-family conflict has a negative consequence on well-being while work-family enhancement can offset some of these impacts. Given that SBOs play a fundamental role in Australia's economy and production, this research is necessary to develop interventions for the government that will best address the work-family conflict that SBO experiences. Government officials should examine the work and family environment and offer assistance so SBOs can pursue their careers without hindrances. The implementation of interventions will help in building healthier work and family lives, and therefore improve the health and well-being of SBOs.

The practical implications of our research for SBOs revolve around acknowledging the importance of work-family management to their psychological health and safety. Psychologically ill individuals may not be able to perform well, likewise ill-being SBOs may not be able to effectively manage successful ventures. Thus, it is crucial to reduce work-family conflict and increase work-family enhancement in order to provide SBOs with a better work-family balance. There should be individual and organizational coping interventions developed to assist SBOs achieve the most positive work-family balance and well-being. Work-family management should be a part of managing their business and expectation. For public policy makers, existing small business support programs should extend from traditional means (i.e., financial and business advisory services) to work-family management strategies and counseling services for this occupation. 


\section{References}

Abbey, Antonia, David J. Abramis, and D. Caplan. 2010. "Basic and Applied Social Psychology Effects of Different Sources of Social Support and Social Conflict on Emotional WellBeing." Basic and Applied Social Psychology 6 (2):111-29.

Abele, Andrea E., and Daniel Spurk. 2009. "How Do Objective and Subjective Career Success Interrelate Over Time?" Journal of Occupational and Organizational Psychology 82 (4):803-24.

Adkins, C. L., S. A., Samaras, S. W., Gilfillan, and W. E. McWee. 2013. "The Relation Ship Between Owner Characteristics, Company Size, and the Work-Family Culture and Policies of Women-Owned Businesses." Journal of Small Business Management 51 (2):196-214.

Aiken, Leona S., Stephen G. West, and Raymond R. Reno. 1991. Multiple Regression. Newbury Park, CA: Sage Publications.

Aryee, Samuel, Ekkirala S. Srinivas, and Hwee Hoon Tan. 2005. "Rhythms of Life: Antecedents and Outcomes of Work-Family Balance in Employed Parents." The Journal of Applied Psychology 90 (1):132-46.

Australian Bureau of Statistics. "Small business in Australia." Accessed June 25, 2015. http:// www.abs.gov.au/ausstats/abs@.nsf/mf/1321.0.

Barnett, Rosalind, Nancy L. Marshall, and Aline Sayer. 1992. "Positive-Spillover Effects from Job to Home: A Closer Look." Women \& Health 19 (2-3):13-41.

Barnett, Rosalind, and Janet Shibley Hyde. 2001. "Women, Men, Work, and Family." American Psychologist 56 (10):781-96.

Baron, Robert. 2004. "Potential Benefits of the Cognitive Perspective: Expanding Entrepreneurship's Array of Conceptual Tools." Journal of Business Venturing 19 (2):169-72.

Beehr, Terry A., Suzanne J. Farmer, Sharon Glazer, David M. Gudanowski, and Vandana Naig Nair. 2003. "The Enigma of Social Support and Occupational Stress: Source Congruence and Gender Role Effects." Journal of Occupational Health Psychology 8 (3):220-31.

Besser, Terry L. 1999. "Community Involvement and the Perception of Success among Small Business Operators in Small Towns.” Journal of Small Business Management 37 (4):16.

Bolger, Niall, Adam Zuckerman, and Ronald C. Kessler. 2000. "Invisible Support and Adjustment to Stress." Journal of Personality and Social Psychology 79 (6):953-61.

Bond, James, Ellen Galinsky, and Jennifer Swansberg. 1998. The 1997 National Study of the Changing Workforce. New York: Families and Work Institute.

Boyar, Scott L., and Donald C. Mosley. 2007. "The Relationship between Core Self-Evaluations and Work and Family Satisfaction: The Mediating Role of Work-Family Conflict and Facilitation." Journal of Vocational Behavior 71 (2):265-81.

Bradburn, Norman, M. 1969. The Structure of Psychological Well-Being. Chicago: Aldine.

Butler, Adam B., Joseph G. Grzywacz, Brenda L. Bass, and Kirsten D. Linney. 2005. "Extending the Demands-Control Model: A Daily Diary Study of Job Characteristics, Work-Family Conflict and Work-Family Facilitation." Journal of Occupational \& Organizational Psychology 78 (2):155-69.

Carlson, Dawn S., and Pamela L. Perrewé. 1999. "The Role of Social Support in the StressorStrain Relationship: An Examination of Work-Family Conflict." Journal of Management 25 (4):513-40.

Chaganti, Radha, and Joy A. Schneer. 1994. "A Study of the Impact of Owner's Mode of Entry on Venture Performance and Management Patterns." Journal of Business Venturing 9 (3): 243-60. 
Chay, Yue Wah. 1993. "Social Support, Individual Differences and Well-Being : A Study of Small Business Entrepreneurs and Employees." Journal of Occupational and Organizational Psychology 66 (4):285-302.

Chen, Zheng, Gary N. Powell, and Jeffrey H. Greenhaus. 2009. "Work-to-Family Conflict, Positive Spillover, and Boundary Management: A Person-Environment Fit Approach." Journal of Vocational Behavior 74 (1):82-93.

Chu, Po, Donald A. Saucier, and Eric Hafner. 2010. "Meta-Analysis of the Relationships between Social Support and Well-Being in Children and Adolescents." Journal of Social \& Clinical Psychology 29 (6):624-45.

Clark, S. C. 2000. “Work/Family Border Theory: A New Theory of Work/Family Balance." Human Relations 53 (6):747-70.

Cole, Kenneth, Anne Daly, and Anita Mak. 2009. "Good for the Soul: The Relationship between Work, Wellbeing and Psychological Capital." The Journal of Socio-Economics 38 (3):464-74.

Cummins, Robert A. 1996. "The Domains of Life Satisfaction: An Attempt to Order Chaos." Social Indicators Research 38 (3):303-28.

Daniel, Stefanie, and Sabine Sonnentag. 2014. "Work to Non-Work Enrichment: The Mediating Roles of Positive Affect and Positive Work Reflection." Work \& Stress 28 (1):49-66.

De Bruin, Anne, and Ann Dupuis. 2004. "Work-Life Balance ?: Insights From Non-Standard Work." New Zealand Journal of Employment Relations 29 (1):21-37.

Department of Innovation Industry, Science and Research 2011 (DIISR 2011). "Key Statistics: Australian Small Business.” Accessed June 25, 2015. http://www.treasury.gov.au/ PublicationsAndMedia/Publications/2011/sml-bus.

Department of Innovation Industry, Science and Research 2012 (DIISR 2012). "Australian Small Business: Key Statistics and Analysis." Accessed June 25, 2015. http://www.treasury.gov. au/PublicationsAndMedia/Publications/2012/sml-bus.

Dess, Gregory G. 1984. “Measuring Organizational Performance in the Absence of Objective Measures: The Case of the Privately-Held Firm and Conglomerate Business Unit." Strategic Management Journal 5 (3):265-73.

Diener, Ed, Eunkook M. Suh, Richard E. Lucas, and Heidi L. Smith. 1999. "Subjective Well-Being: Three Decades of Progress.” Psychological Bulletin 125 (2):276-302.

Dyer, W. Gibb. 2003. "The Family: The Missing Variable in Organizational Research.” Entrepreneurship Theory and Practice 27 (4):401-16.

Edwards, Jeffrey R., and Nancy P. Rothbard. 2000. "Mechanisms Linking Work and Family: Clarifying the Relationship between Work and Family Constructs." The Academy of Management Review 25 (1):178.

Ernst Kossek, Ellen, and Cynthia Ozeki. 1998. "Work-Family Conflict, Policies, and the Job-Life Satisfaction Relationship: A Review and Directions for Organizational Behavior-Human Resources Research." Journal of Applied Psychology 83 (2):139-49.

Faul, Franz, Edgar Erdfelder, Axel Buchner, and Albert-Georg Lang. 2009. "Statistical Power Analyses Using G*Power 3.1: Tests for Correlation and Regression Analyses.” Behavior Research Methods 41 (4):1149-60.

Field, Andy. 2013. Discovering Statistics Using SPSS: And Sex, Drugs and Rock'n'roll. London: Sage.

Ford, Michael T., Beth A. Heinen, and Krista L. Langkamer. 2007. "Work and Family Satisfaction and Conflict: A Meta-Analysis of Cross-Domain Relations." The Journal of Applied Psychology 92 (1):57-80. 
Frone, Michael R., Marcia Russell, and M. Lynne Cooper. 1992. "Antecedents and Outcomes of Work-Family Conflict: Testing a Model of the Work-Family Interface." The Journal of Applied Psychology 77 (1):65-78.

Frone, Michael R., John K. Yardley, and Karen S. Markel. 1997. "Developing and Testing an Integrative Model of the Work-Family Interface." Journal of Vocational Behavior 50 (2): 145-67.

Gareis, Karen C., Rosalind Barnett, Karen A. Ertel, and Lisa F. Berkman. 2009. “Work-Family Enrichment and Conflict: Additive Effects, Buffering, or Balance ?" Journal of Marriage \& Family 71 (3):696-707.

Gorgievski, M., M. E., Ascalon, and U. Stephan. 2011. "Small Business Owners' Success Criteria, a Values Approach to Personal Differences." Journal of Small Business Management 49 (2):207-32.

Greenhaus, Jeffrey H., and Gary N. Powell. 2006. "When Work and Family Are Allies: A Theory of Work-Family Enrichment.” Academy of Management Review 31 (1):72-92.

Greenhaus, Jeffrey H., and Nicholas J. Beutell. 1985. "Sources of Conflict between Work and Family Roles." The Academy of Management Review 10 (1):76.

Greenhaus, Jeffrey H., Jonathan C. Ziegert, and Tammy D. Allen. 2012. "When Family-Supportive Supervision Matters: Relations Between Multiple Sources of Support and Work-Family Balance." Journal of Vocational Behavior 80 (2):266-75.

Grönlund, Anne. 2007. "More Control, Less Conflict? Job Demand? Control, Gender and Work Family Conflict." Gender, Work \& Organization 14 (5):476-97.

Grzywacz, Joseph G., and Nadine F. Marks. 2000. "Reconceptualizing the Work-Family Interface: An Ecological Perspective on the Correlates of Positive and Negative Spillover between Work and Family." Journal of Occupational Health Psychology 5 (1):111-26.

Grzywacz, Joseph G., and Brenda L. Bass. 2003. "Work, Family, and Mental Health: Testing Different Models of Work-Family Fit." Journal of Marriage \& Family 65 (1):248-61.

Gudmunson, Clinton G., Sharon M. Danes, J. D. Werbel, and J. T.-C. Loy. 2009. "Spousal Support and Work-Family Balance in Launching a Family Business." Journal of Family Issues 30 (8):1098-121.

Hahn, V. C., M. Frese, C., Binnewies, and A., Schmitt. 2012. "Happy and Proactive? The Role of Hedonic and Eudaimonic Well-Being in Business Owners' Personal Initiative."

Entrepreneurship Theory and Practice 36 (1):97-114.

Halbesleben, Jonathon R. B., Anthony R. Wheeler, and Ana Maria Rossi. 2012. "The Costs and Benefits of Working with One's Spouse: A Two-Sample Examination of Spousal Support, Work-Family Conflict, and Emotional Exhaustion in Work-Linked Relationships." Journal of Organizational Behavior 33 (5):597-615.

Hanson, Ginger C., Leslie B. Hammer, and Cari L. Colton. 2006. "Development and Validation of a Multidimensional Scale of Perceived Work-Family Positive Spillover." Journal of Occupational Health Psychology 11 (3):249-65.

Häusser, Jan Alexander, Andreas Mojzisch, Miriam Niesel, and Stefan Schulz-Hardt. 2010. "Ten Years on: A Review of Recent Research on the Job Demand-Control (-Support) Model and Psychological Well-Being." Work \& Stress 24 (1):1-35.

Heaney, Catherine A., Barbara A. Israel, and James S. House. 1994. "Chronic Job Insecurity among Automobile Workers: Effects on Job Satisfaction and Health." Social Science \& Medicine 38 (10):1431-7.

Henderson, Scott, Paul Duncan-Jones, Helen McAuley, and Ritchie Karen. 1978. "The Patient's Primary Group." British Journal of Psychiatry 132 (1):74-86. 
Jennings, Jennifer E., and Megan S. McDougald. 2007. "Work-Family Interface Experiences and Coping Strategies: Implications for Entrepreneurship Research and Practice." Academy of Management Review 32 (3):747-60.

John, O. P., and V. Benet-Martínez. 2000. "Measurement, Scale Construction, and Reliability". In Handbook of research methods in social and personality psychology, edited by H. T. Reis and C. M. Judd, 339-369. New York, NY: Cambridge University Press.

Keyes, Corey L. M., Dov Shmotkin, and Carol D. Ryff. 2002. "Optimizing Well-Being: The Empirical Encounter of Two Traditions." Journal of Personality and Social Psychology 82 (6):1007-22.

Kilkenny, Maureen, Laura Nalbarte, and Terry Besser. 1999. "Reciprocated Community Support and Small Town-Small Business Success." Entrepreneurship \& Regional Development 11 (3):231-46.

Kim, Jean Lee Siew, and Choo Seow Ling. 2001. "Work-Family Conflict of Women Entrepreneurs in Singapore." Women in Management Review 16 (5):204-21.

Kinnunen, Ulla, and Saija Mauno. 1998. "Antecedents and Outcomes of Work-Family Conflict among Employed Women and Men in Finland." Human Relations 51 (2):157-77.

Kirkwood, Jodyanne, and Beth Tootell. 2008. "Is Entrepreneurship the Answer to Achieving Work-Family Balance?” Journal of Management \& Organization 14 (2):285-302.

Kline, Rex B. 2011. Principles and Practice of Structural Equation Modeling. New York: The Guilford Press.

Kossek, Ellen Ernst, Shaun Pichler, Todd Bodner, and Leslie B. Hammer. 2011. "Workplace Social Support and Work-Family Conflict: A Meta-Analysis Clarifying the Influence of General and Work-Family-Specific Supervisor and Organizational Support." Personnel Psychology 64 (2):289-313.

Lee, S. M., and S. J. Peterson. 1998. "Culture, Entrepreneurial Orientation and Global Competitiveness." Journal of World Business 35 (4):401-16.

Linley, P. Alex, John Maltby, Alex M. Wood, Gabrielle Osborne, and Robert Hurling. 2009. "Measuring Happiness: The Higher Order Factor Structure of Subjective and Psychological Well-Being Measures." Personality and Individual Differences 47 (8):878-84.

Loscocco, Karyn, and Anne R. Roschelle. 1991. "Influences on the Quality of Work and Nonwork Life: Two Decades in Review.” Journal of Vocational Behavior 39 (2):182-225.

Maertz, Carl P, and Scott L. Boyar. 2011. "Work-Family Conflict, Enrichment, and Balance under 'Levels' and 'Episodes' Approaches.” Journal of Management 37 (1):68-98.

Marjan, J., M. Gorgievski, Evelina Ascalon, and Ute Stephan. 2011. "Small Business Owners' Success Criteria, a Values Approach to Personal Differences." Journal of Small Business Management 49 (2):207-32.

Marshall, Nancy L., and Rosalind C. Barnett. 1993. "Work-Family Strains and Gains among TwoEarner Couples.” Journal of Community Psychology 21 (1):64-79.

McDonald, Peter, and Helen Brownlee. 1993. "High-Rise Parenting: Raising Children in Melbourne's High-Rise Estates.” Family Matters 36 (1):4-15.

McNall, Laurel A., Jessica M. Nicklin, and Aline D. Masuda. 2009. "A Meta-Analytic Review of the Consequences Associated with Work-Family Enrichment." Journal of Business and Psychology 25 (3):381-96.

Michel, Jesse S., Jacqueline K. Mitchelson, Shaun Pichler, and Kristin L. Cullen. 2010. "Clarifying Relationships among Work and Family Social Support, Stressors, and Work-Family Conflict." Journal of Vocational Behavior 76 (1):91-104. 
Netemeyer, Richard G., James S. Boles, and Robert McMurrian. 1996. "Development and Validation of Work-Family Conflict and Family-Work Conflict Scales." Journal of Applied Psychology 81 (4):400-10.

Parasuraman, Saroj, Jeffrey H. Greenhaus, and Cherlyn Skromme Granrose. 1992. "Role Stressors, Social Support, and Well-Being among Two-Career Couples." Journal of Organizational Behavior 13 (4):339-56.

Parasuraman, Saroj, and C. A. Simmers. 2001. "Type of Employment, Work-Family Conflict and Well-Being: A Comparative Study." Journal of Organizational Behavior 22 (5): 551-68.

Parasuraman, Saroj, Yasmin S. Purohit, Veronica M. Godshalk, and Nicholas J. Beutell. 1996. "Work and Family Variables, Entrepreneurial Career Success, and Psychological WellBeing." Journal of Vocational Behavior 48 (3):275-300.

Phelan, Jo, Joseph E. Schwartz, Evelyn J. Bromet, Mary A. Dew, David K. Parkinson, Herbert C. Schulberg, Leslie O. Dunn, Howard Blane, and E. Carroll Curtis. 1991. "Work Stress, Family Stress and Depression in Professional and Managerial Employees." Psychological Medicine 21 (4):999-1012.

Pinquart, Martin, and Silvia Sörensen. 2000. "Influences of Socioeconomic Status, Social Network, and Competence on Subjective Well-Being in Later Life: A Meta-Analysis." Psychology and Aging 15 (2):187-224.

Pirkis, Jane E., Philip M. Burgess, Pia K. Kirk, Sarity Dodson, Tim J. Coombs, and Michelle K. Williamson. 2005. "A Review of the Psychometric Properties of the Health of the Nation Outcome Scales (HoNOS) Family of Measures.” Health and Quality of Life Outcomes 3 (1):76.

Podsakoff, Philip M., Scott B. MacKenzie, Jeong-Yeon Lee, and Nathan P. Podsakoff. 2003. "Common Method Biases in Behavioral Research: A Critical Review of the Literature and Recommended Remedies." Journal of Applied Psychology 88 (5):879-903.

Powell, Gary N., and Kimberly A. Eddleston. 2013. "Linking Family-to-Business Enrichment and Support to Entrepreneurial Success: Do Female and Male Entrepreneurs Experience Different Outcomes?" Journal of Business Venturing 28 (2):261-80.

Rice, Robert W., Michael R. Frone, and Dean B. Mcfarlin. 1992. "Work-Nonwork Conflict and the Perceived Quality of Life." Journal of Organizational Behavior 13 (2):155-68.

Ruderman, Marian N., Patricia J. Ohlott, Kate Panzer, and Sara N. King. 2002. "Benefits of Multiple Roles for Managerial Women.” Academy of Management Journal 45 (2):369-86.

Ryff, Carol D., and Corey Lee M. Keyes. 1995. "The Structure of Psychological Well-Being Revisited." Journal of Personality and Social Psychology 69 (4):719-27.

Ryff, Carol D. 1989. "Happiness Is Everything, or Is It? Explorations on the Meaning of Psychological Well-Being." Journal of Personality and Social Psychology 57 (6):1069-81.

Schimmack, Ulrich, Phanikiran Radhakrishnan, Shigehiro Oishi, Vivian Dzokoto, and Stephan Ahadi. 2002. "Culture, Personality, and Subjective Well-Being: Integrating Process Models of Life Satisfaction." Journal of Personality and Social Psychology 82 (4):582-93.

Shelton, Lois M. 2006. "Female Entrepreneurs, Work-Family Conflict, and Venture Performance: New Insights into the Work-Family Interface." Journal of Small Business Management 44 (2):285-97.

Shockley, Kristen M., and Neha Singla. 2011. "Reconsidering Work-Family Interactions and Satisfaction: A Meta-Analysis.” Journal of Management 37 (3):861-86.

Siemsen, Enno, Aleda Roth, and Pedro Oliveira. 2009. "Common Method Bias in Regression Models with Linear, Quadratic, and Interaction Effects." Organizational Research Methods 13 (3):456-76. 
Srivastava, Abhishek, Edwin A. Locke, and Kathryn M. Bartol. 2001. "Money and Subjective Well-Being: It's Not the Money, It's the Motives." Journal of Personality and Social Psychology 80 (6):959-71.

Steel, Piers, Joseph Schmidt, and Jonas Shultz. 2008. "Refining the Relationship between Personality and Subjective Well-Being." Psychological Bulletin 134 (1):138-61.

Stephan, Ute, and Ulrike Roesler. 2010. "Health of Entrepreneurs versus Employees in a National Representative Sample." Journal of Occupational and Organizational Psychology 83 (3):717-38.

Stuart, Tony E., and Olav Sorenson. 2005. "Social Networks and Entrepreneurship." In Handbook of Entrepreneurship Research: Disciplinary Perspectives, edited by Sharon A. Alvarez, Rajshree Agarwal, and Olav Sorenson, 233-52. New York: Springer.

Summerfield, Michelle, Freidin Simon, Hahn Markus, Ittak Peter, Ning Li, Ninette Macalalad, Watson Nicole, Wilkins Roger, and Wooden Mark. 2011. HILDA user manual - release 12. Melbourne Institute of Applied Economic and Social Research, University of Melbourne. Accessed June 25, 2015. http://www.melbourneinstitute.com/hilda/.

Tabachnick, Barada G., and Linda S. Fidell. 2007. Using Multivariate Statistics. Boston: Pearson/Ally \& Bacon.

Taylor, Marcia F., Brice John, Buck Nick, and Elaine Prentice-Lane. 2010. British Household Panel Survey User Manual. Institute for Social \& Economic Research, University of Essex. Accessed June 25, 2015. http://www.iser.essex.ac.uk/bhps/documentation/pdf_versions/ volumes/bhpsvola.pdf.

Wadsworth, Lori L., and Bradley P. Owens. 2007. "The Effects of Social Support on Work-Family Enhancement and Work-Family Conflict in the Public Sector." Public Administration Review 67 (1):75-86.

Ware, John E., Mark Kosinski, Diane M. Turner-Bowker, and Barbara Gandek. 2002. How to Score Version 2 of the SF-12® Health Survey (with a Supplement Documenting Version 1). Lincoln, RI: QualityMetric Incorporated.

Wayne, Julie Holliday, Nicholas Musisca, and William Fleeson. 2004. "Considering the Role of Personality in the Work-Family Experience: Relationships of the Big Five to Work-Family Conflict and Facilitation.” Journal of Vocational Behavior 64 (1):108-30. Wayne, Julie Holliday, Amy E. Randel, and Jaclyn Stevens. 2006. "The Role of Identity and Work-Family Support in Work-Family Enrichment and Its Work-Related Consequences." Journal of Vocational Behavior 69 (3):445-61.

\section{Appendices}

\section{Appendix A.1}

Summary of the items used as a measure of Work-to-Family Conflict/Interference

1. Because of the requirements of my job, I miss out on home or family activities that I would prefer to participate in.

2. Because of the requirements of my job, my family time is less enjoyable and more pressured. 
3. Working causes me to miss out on some of the rewarding aspects of being a parent.

4. Because of the requirements of my job, I have too little time for my family.

\section{Appendix A.2}

Summary of the items used as a measure of Work-Family Enhancement

1. Having both work and family responsibility challenges me to be the best I can be.

2. Working makes me feel good about myself, which is good for my children.

3. My work has a positive effect on my children.

4. Working helps me better appreciate the time I spend with my children.

5. The fact that I am working makes me a better parent.

\section{Appendix A.3}

Summary of the items used as a measure of Social Support

1. People don't come to visit me as often as I would like.

2. I often need help from other people but I can't get it.

3. I seem to have a lot of friends.

4. I don't have anyone that I can confide in.

5. I have no one to lean on in times of trouble.

6. I often feel very lonely.

\section{Appendix A.4}

Summary of the items used as a measure of Mental Health

1. Did you feel full of life?

2. Have you been a nervous person?

3. Have you felt so down in the dumps that nothing could cheer you up?

4. Have you felt calm and peaceful?

5. Did you have a lot of energy?

6. Have you felt down?

7. Did you feel worn out?

8. Have you been a happy person?

9. Did you feel tired? 


\section{Appendix A.5}

Summary of the items used as a measure of Job Satisfaction.

How satisfied are you with:

1. Your total pay?

2. Your job security?

3. The work itself (what you do)?

4. The hours you work?

5. The flexibility available to balance work and nonwork commitments?

6. All things considered, how satisfied are you with your job?

\section{Appendix A.6}

Summary of the items used as a measure of Family Satisfaction How satisfied are you with:

1. Your relationship with your partner?

2. Your relationship with your children?

3. Your partner's relationship with your children?

4. Your relationship with your stepchildren?

5. How well the children in the household get along with each other?

6. Your relationship with your parents?

7. Your relationship with your step-parents?

8. Your relationship with your (most recent) former spouse or partner?

\section{Appendix A.7}

Summary of the items used as a measure of Life Satisfaction.

How satisfied are you with

1. The home in which you live?

2. Your employment opportunities?

3. Your financial situation?

4. How safe you feel?

5. Feeling part of your local community?

6. Your health?

7. The neighborhood in which you live?

8. The amount of free time you have?

9. All things considered, how satisfied are you with your life? 


\section{Bionotes}

\section{Hieu Nguyen}

Mr Hieu is a research student at School of Counselling and Psychology, Queensland University of Technology.

\section{Sukanlaya Sawang}

Dr Sukanlaya's research primarily focuses on small business and wellbeing. She has an extensive array of quality research publications in this area (including cross-cultural studies), experience in managing large research grants, and a strong collaborative research background with scholars from Asian countries. Suknalaya has also provided consulting services for small businesses in Asia and Australia; training for small businesses through The Asian Productivity Organization (a regional intergovernmental organisation which aims to build the sustainable socioeconomic development of Asia and the Pacific); developed academic courses, research projects and publications relating to small businesses. She is an active member of the Australian Centre for Entrepreneurship Research (ACE) and the executive board of the Asian Cognitive Behavioural Therapy Association. 